ammoniacal solution of borontrimethylmonoammine is non-conducting. Thus diborane is a dibasic, tetraborane a tetrabasic acid, and they may be formulated thus: $\mathrm{H}_{2}\left[\mathrm{~B}_{2} \mathrm{H}_{4}\right]$ and $\mathrm{H}_{4}\left[\mathrm{~B}_{4} \mathrm{H}_{6}\right]$.

The unsaturated character of these hydrides has been proved by both spectroscopic and chemical evidence. Thus diborane and ethylene give similar absorption bands, where ethane shows none at all, in the region between 210 and $186 \mu \mu$. Moreover, when shaken with alkali amalgam, the boranes react additively with the alkali metals thus:

$$
\mathrm{B}_{2} \mathrm{H}_{6}+2 \mathrm{~K}=2 \mathrm{~K}+\left[\mathrm{B}_{2} \mathrm{H}_{6}\right]^{--} \text {. }
$$

A molecular weight determination deduced from measurement of its diamagnetic susceptibility shows that the borane molecule has not been ruptured into simpler molecules in this reaction. The resulting potassium salt can be sublimed unchanged at about $400^{\circ} \mathrm{C}$., so that the bivalent negative ion $\mathrm{B}_{2} \mathrm{H}_{6}--$ with an ethane-like structure is much more stable than the unsaturated 'ethylenic' molecule $\mathrm{B}_{2} \mathrm{H}_{6}$, for which the formula $2 \mathrm{H}+\left[\mathrm{BH}_{2}: \mathrm{BH}_{2}\right]^{-}-$must now be adopted.

The unsaturated character of diborane accounts also for its reactions with water and with hydrogen chloride, since in both cases the additive products which are first formed split off hydrogen to produce a new unsaturated product; this then reacts further in the same way until we arrive at boric acid or boron polyhalides as final products. Some of the intermediate compounds have even been isolated. Similarly, the formula of tetraborane is written thus :

$$
4 \mathrm{H}+\left[\mathrm{BH}_{2}: \mathrm{BH} \cdot \mathrm{BH}: \mathrm{BH}_{2}\right)^{---}
$$

Two different groups of hydrides have been recognized, corresponding with the general formulæ $\mathrm{B}_{n} \mathrm{H}_{n+4}$ and $\mathrm{B}_{n} \mathrm{H}_{n+6}$. At present, only the first mombers of each group have been investigated experimentally, but in both cases the chemical evidence has been supported by that based on measurements of parachor, dipole moments, magnetic properties and ultra-violet absorption spectra.

\section{Plankton Research and Sea Fisheries}

A RECENT publication by R. E. Savage and R. S. Wimpenny ("Phytoplankton and the Herring", Part 2 (1933 and 1934), Min. Agric. Fish., Fishery Invest., Ser. II, 15, No. I (1936), pp. 1-88. London: H.M. Stationery Office, 1936. $4 s .6 d$. gives detailed information on the plankton conditions in the southern North Sea and their relations with the herring fishery in the years 1933 and 1934. This is a continuation of work already begun in 1921 and follows on a previous report for the years 1921--32.

The year 1933 was remarkable for unusually dense patches of the diatoms Rhizosolenia styliformis and Biddulphia sinensis. The former is associated with the current system in the neighbourhood of the south-west Dogger Bank Swirl; and the unusual degree of production in 1933 appeared to owe its origin to a strong incursion of oceanic bottom water, from the north, rich in nutrient salts. The arrival of the East Anglian herring shoals was delayed by these diatom patches in October 1933. A remarkable condition is recorded in May 1933, when a large area was covered with masses of the diatom Coscinodiscus concinnus to a depth of four feet, in which several guillemots and puffins were found floating dead. This was apparently being eaten by fulmar petrels.
Increasing attention to detail in this long-continued plankton programme is producing indications of new lines for research. The relation between the distribution and drift of the plankton with the water circulation is gradually being disclosed, as well as certain interrelationships between the phytoplankton and the zooplankton which call for further observation. Notable among these is evidence that higher proportions of the eggs and young stages of plankton animals are to be found within the diatom patches than in the surrounding areas. Adult plankton animals and herrings also appear to be massed against the edges of the phytoplankton patches. Evidence is fortheoming that the distribution of the young stages of the animals may be associated with the high oxygen content of the diatom patches.

The authors intend to investigate this problem further, but whatever be the true significance, it is clear that this continued routine research is developing on expanding lines which will lead to a better understanding of the biology of the plankton in the future. The work is carried on throughout in close collaboration with the hydrographers.

\section{University Events}

LONDON.- The title of professor of biochemistry in the University has been conferred on Dr. A. C. Chibnall in respect of the post held by him at the Imperial College-Royal College of Science.

The title of emeritus professor of mining geology in the University has been conferred on Prof. C. G. Cullis, on his retirement from the University professorship of mining geology at the Imperial College -Royal College of Science.

Dr. F. G. Gregory has been appointed as from October 1 to the University chair of plant physiology tenable at the Imperial College-Royal College of Science. Since 1931, he has been assistant director of the Research Institute of Plant Physiology at the Imperial College.

The following have been appointed fellows of King's College : Prof. F. A. P. Aveling, professor of psycho. logy since 1931; Miss Agnes S. Paul, lecturer in classies since 1932; Col. G. S. Szlumper, assistant general manager of the Southern Railway, and a vice-president of the Engineering Branch of the Old Students' Association; Mr. S. J. Worsley, academic registrar and acting principal of the University.

Prof. Raymond Pearl, professor of biology in the School of Hygiene and Public Health of Johns Hopkins University, has been appointed Heath Clark lecturer for the year 1937.

The degree of D.Sc. in mathematics has been conferred on A. C. Offord, of University College, and that of D.Sc in physiology on Miss M. M. A. Murray, a recognized teacher at Bedford College.

Oxford.-Prof. A. G. Tansley, Sherardian professor of botany and fellow of Magdalen College since 1927 , is retiring under the age-limit as from July 31 , 1937. Applications for the vacant professorship should reach the Registrar by April 17. The Board of the Faculty of Biological Sciences has recommended that the new professor should be primarily an ecologist.

The Nuffield professors, Prof. H. W. B. Cairns, Balliol, and Prof. R. R. Macintosh, Pembroke, and also Dr. S. Zuckerman, Christ Church, have received the degree of M.A. by decree. 